\title{
Presence of Hypogammaglobulinemia - A Risk Factor of Mortality in Patients with Severe Sepsis, Septic Shock, and SIRS
}

\author{
Průcha M. ${ }^{1}$, Zazula R. ${ }^{2}$, Herold I. ${ }^{3}$, Dostál M. ${ }^{4}$, Hyánek T. ${ }^{5}$, Bellingan G. ${ }^{6}$ \\ ${ }^{1}$ Department of Clinical Biochemistry, Hematology and Immunology, Na Homolce \\ Hospital, Prague, Czech Republic; \\ 2Department of Anesthesiology and Intensive Care, First Faculty of Medicine, \\ Charles University in Prague and Thomayer Hospital, Prague, Czech Republic; \\ 32Department of Anaesthesiology and Intensive Care Medicine, Klaudian's Hospital, \\ Mladá Boleslav, Czech Republic; \\ ${ }^{4}$ Institute of Experimental Medicine, Academy of Sciences, Prague, Czech Republic; \\ ${ }^{5}$ Department of Intensive Care Medicine, Na Homolce Hospital, Prague, \\ Czech Republic; \\ ${ }^{6}$ UCL Department of Medicine and NIHR University College London Hospitals, \\ Biomedical Research Centre, London, United Kingdom
}

Received September 26, 2013; Accepted November 25, 2013.

Key words: Severe sepsis - Septic shock - SIRS - Hypogammaglobulinemia Mortality

Abstract: In this retrospective study we assessed the frequency of hypogammaglobulinemia in 708 patients with SIRS, severe sepsis and septic shock. We evaluated the relationship between hypogammaglobulinemia IgG, IgM and 28 day mortality. Total of 708 patients and 1,513 samples were analyzed. In the three subgroups we investigated, patients met the criteria of SIRS, severe sepsis and septic shock. IgG hypogammaglobulinemia was demonstrated in 114 patients with severe sepsis (25.2\%), 11 septic shock patients (24.4\%), and in 29 SIRS patients (13.9\%). IgM hypogammaglobulinemia was documented in 55 patients with severe sepsis (12.2\%), 6 septic shock patients (13.3\%), and in 17 SIRS patients (8.1\%). Mortality of patients with severe sepsis and normal $\lg G$ levels was significantly lower (111 patients; $32.8 \%$ ) compared with those with IgG hypogammaglobulinemia (49 patients; 43.0\%; $p=0.001$ ). Mortality of patients with septic shock and $\lg G$ hypogammaglobulinemia $(n=5)$ was significantly higher compared with those with normal lgG levels ( $45.5 \%$ vs. $38.2 \%$; $p=0.001)$. Mortality of patients with severe

Mailing Address: Assoc. Prof. Miroslav Průcha, MD., PhD., Department of Clinical Biochemistry, Hematology and Immunology, Na Homolce Hospital, Roentgenova 2, 15030 Prague 5, Czech Republic; Phone: +420 257273 150; Fax: +420 257272 965; e-mail: miroslav.prucha@homolka.cz 
sepsis and IgM hypogammaglobulinemia did not differ from that of patients with normal IgM levels (37.0 vs. $41.8 \%$ ). Mortality of patients with septic shock and IgM hypogammaglobulinemia was significantly higher compared with those with normal IgM levels ( $50 \%$ vs. $38.5 \%$; $p=0.0001)$. This study documented relatively high incidence of hypogammaglobulinemia $\lg G$ and $\operatorname{lgM}$ in patients with severe sepsis, septic shock and SIRS respectively. The presence of IgG hypogammaglobulinemia in patients with severe sepsis is independent factor of mortality.

\section{Introduction}

The pathogenesis of sepsis is associated with dysregulation of the innate and adaptive immune system. The underlying mechanism of the adaptive immune system includes antibodies-immunoglobulins. While having multiple functions (Casadevall and Pirofski, 2011), protection against infection is among the most important. Intravenous administration of immunoglobulins (IVIG) is a therapeutic immunomodulatory option in septic patients. A number of studies have documented a beneficial effect of IVIG on mortality rates for this patient population, but most of the trials were small, and the evidence of efficacy is limited (Alejandria et al., 2013). Current guidelines for sepsis management do not recommend IVIG use in the treatment of septic patients. Only a limited number of trials have been designed to determine the incidence of hypogammaglobulinemia in patients with systemic inflammatory response syndrome (SIRS), severe sepsis, and septic shock.

Our retrospective review was designed to determine the incidence of hypogammaglobulinemia in patients with SIRS, severe sepsis, and septic shock hospitalized in intensive care units (ICUs). Another goal was to determine the association between the incidence of hypogammaglobulinemia and mortality in individual patient groups.

\section{Patients and Methods}

Between 2003 and 2010, a total of 708 patients and 1,513 samples from three Czech hospitals were analyzed. The group included three basic subgroups. In the first and the second, the patients met the criteria severe sepsis or septic shock; our study did not include patients with community-acquired septic shock, they were exclusively patients with ICU-acquired septic shock. The third - control group - included patients after cardiothoracic and general surgery fulfilling SIRS criteria without the presence of infection. Given the retrospective design of the study and the fact no active intervention other than standard medical treatment was employed in all cases, the Institutional Review Board deemed informed consent unnecessary. The study was approved by the Institutional Review Boards of the Prague-based Na Homolce Hospital and Thomayer Hospital, and Klaudian's Hospital in Mladá Boleslav (a district hospital in Central Bohemia). The study has 
been performed in accordance with the 1964 Declaration of Helsinki and its later amendments.

Table 1 - Baseline characteristics of the patients

\begin{tabular}{|c|c|c|c|c|c|c|c|}
\hline \multirow[b]{2}{*}{ Diagnosis } & \multicolumn{2}{|c|}{ Sex } & \multirow{2}{*}{$\begin{array}{l}\text { Age } \\
\text { (years) }\end{array}$} & \multirow{2}{*}{$\begin{array}{c}\text { PCT } \\
\text { (med) } \\
(\mathrm{ng} / \mathrm{ml})\end{array}$} & \multirow{2}{*}{$\begin{array}{c}\text { CRP } \\
(\mathrm{mg} / \mathrm{ml})\end{array}$} & \multirow[b]{2}{*}{ Apache II } & \multirow{2}{*}{$\begin{array}{c}\text { Mortality } \\
(\%)\end{array}$} \\
\hline & $M$ & $\mathrm{~F}$ & & & & & \\
\hline SIRS (211) & 143 & 68 & $62.3 \pm 17$ & 0.71 & 85 & $15 \pm 6$ & 9 \\
\hline Severe sepsis (452) & 290 & 162 & $65.8 \pm 14$ & 2.83 & 126.1 & $21 \pm 7$ & 37.8 \\
\hline Septic shock (45) & 29 & 16 & $67.3 \pm 12$ & 12.3 & 172.3 & $25 \pm 10$ & 42.8 \\
\hline
\end{tabular}

PCT - procalcitonin; CRP - C-reactive protein; Apache II - acute physiology and chronic health evaluation II

\section{Table 2 - Site of infection}

\begin{tabular}{lc}
\hline \multicolumn{1}{c}{ Source of infection } & $\mathrm{n}$ \\
\hline Lung & 233 \\
Abdomen & 138 \\
Urinary & 85 \\
CNS & 12 \\
Catheter & 29 \\
\hline
\end{tabular}

Patients' serum samples were analyzed for IgG, IgA, and IgM levels. SIRS, severe sepsis and septic shock were defined using standard criteria (Levy et al., 2003). The first serum samples were obtained during the first 24 hours after fulfilling criteria. Because the participating centers were not consistent in indicating IVIG use, only the first sample was analyzed. Exclusion criteria included congenital humoral deficiencies, previous (within the last 3 months) administration of IVIG, previous immunosuppressive therapy with systemic corticosteroids (within the last 3 months), established protein-losing enteropathies or nephrotic syndrome, and neoplastic or proliferative hematological diseases.

All patients were evaluated by their demographic and clinical characteristics (Tables 1 and 2). Levels of procalcitonin (PCT), C-reactive protein (CRP) were assessed. The clinical outcomes of patients as well as the results of microbiological blood cultures were analyzed during their hospitalization. Hypogammaglobulinemia is defined as $\lg G$ levels less than 2 SDs below the mean for age. In our study hypogammaglobulinemia were defined as those $<600 \mathrm{mg} / \mathrm{dl}$ for $\mathrm{lgG},<70 \mathrm{mg} / \mathrm{dl}$ for IgA, and $<40 \mathrm{mg} / \mathrm{dl}$ for IgM. Given the literature (Lucas et al., 2010) and our experience with the management of patients with primary immunodeficiency, i.e. common variable immunodeficiency (CVID), we divided our patients with IgG hypogammaglobulinemia into two subgroups, i.e. those with IgG levels of 400-600 mg/dl and those with lgG levels $<400 \mathrm{mg} / \mathrm{dl}$. Patients with CVID 
have shown that $\lg G$ levels $<400 \mathrm{mg} / \mathrm{dl}$ are associated with the development of severe infections.

\section{Statistical analysis}

The descriptive statistics and all tests were performed using STATA 12 software. The Kruskal-Wallis a quality of populations rank test was used for bivariate analyses. Logistic regression was used to analyze associations of low serum levels of immunoglobulins $A, G$ and $M$ with outcome. To create categorical variables, lg levels were dichotomised at $600 \mathrm{mg} / \mathrm{dl}, 70 \mathrm{mg} / \mathrm{dl}$ and $40 \mathrm{mg} / \mathrm{dl}$ for lgG, $\lg \mathrm{A}$ and $\lg \mathrm{M}$, respectively. The significance of associations was determined by the rate ratio (RR), statistically significant probability and a $95 \%$ confidence interval not including the value 1 . Confounders were determined by changes in the regression coefficient of more than $15 \%$ after removal of the variable.

\section{Results}

Patient characteristics by their PCT and CRP levels

A total of 1,513 analyses were performed using samples obtained from our 708 patients. Repeat analyses were undertaken in 117 patients, with only the first values analyzed. Of the 708 patients, 452 and 45 patients met the criteria for severe sepsis and septic shock. Systemic inflammatory response syndrome criteria were met by 211 patients without evidence of an infectious focus. Procalcitonin levels at time of $\lg G$ sampling were significantly higher in patients with severe sepsis (median $2.83 \mathrm{ng} / \mathrm{ml}$, interquartile range (IQR) 1.11-12.88 $\mathrm{ng} / \mathrm{ml}$ ) and septic shock (median $12.3 \mathrm{ng} / \mathrm{ml}$, IQR $2.56-32.18 \mathrm{ng} / \mathrm{ml}$ ) compared with patients with non-infectious SIRS (median $0.71 \mathrm{ng} / \mathrm{ml}$, IQR $0.37-1.36 \mathrm{ng} / \mathrm{ml}$; $\mathrm{p}=0.0001$ ). $\mathrm{C}$-reactive protein levels in the groups of patients with severe sepsis (median $126.1 \mathrm{mg} / \mathrm{ml}$, IQR 80.1-193.2) septic shock (median $172.3 \mathrm{mg} / \mathrm{ml}$, IQR 98.4-280.4) were statistically significantly higher compared with CRP levels in non-infectious SIRS patients (median 85 mg/ml, IQR 54.7-150.9; $\mathrm{p}=0.001$ ).

Presence of hypogammaglobulinemia is associated with increased mortality IgG hypogammaglobulinemia was demonstrated in 114 patients with severe sepsis (25.2\%), 11 septic shock patients (24.4\%), and in 29 SIRS patients (13.9\%).

The incidence of $\lg G$ hypogammaglobulinemia in the groups of patients with severe sepsis and septic shock did not differ significantly. Mortality of patients with severe sepsis and normal lgG levels was significantly lower (111 patients; $32.8 \%$ ) compared with those with $\lg G$ hypogammaglobulinemia (49 patients; $41.2 \%$; $p=0.001$; Figure 1 ). In multivariate logistic regression the odds ratio of not surviving was 2-times higher in patients with hypo $\lg (2.0 ; p=0.002,95 \% \mathrm{Cl} 1.3-3.2)$ than in patients with normal levels of lgG. Mortality of patients with septic shock and documented IgG hypogammaglobulinemia $(n=5)$ was significantly higher compared with those with normal IgG levels ( $45.5 \%$ vs. $38.2 \%$; $p=0.001$; Figure 1 ). Mortality of SIRS 
patients with hypogammaglobulinemia IgG was significantly higher compared with patients without it ( $30 \%$ vs. $10.6 \% ; p=0.001)$. IgA hypogammaglobulinemia was noted in 12 patients with severe sepsis (2.7\%), one septic shock patient $(2.2 \%)$, and 6 SIRS patients (2.3\%). IgA hypogammaglobulinemia and mortality was not assessed because of the small number of patients. IgM hypogammaglobulinemia was documented in 55 patients with severe sepsis (12.2\%), 6 septic shock patients (13.3\%), and in 17 SIRS patients (8.1\%). Mortality of patients with severe sepsis and IgM hypogammaglobulinemia did not differ from that of patients with normal IgM levels (37.0 vs. $41.8 \%$; Figure 2). Mortality of patients with septic shock and IgM hypogammaglobulinemia was significantly higher compared with septic shock patients with normal IgM levels ( $50 \%$ vs. $38.5 \%$; $p=0.001$; Figure 2 ), but very low number of patients were investigated - only in 6 patients with septic shock was documented IgG hypogammaglobulinemia. Mortality of patients with SIRS and IgM hypogammaglobulinemia did not differ from mortality SIRS patients and normal IgM levels.

Severity of hypogammaglobulinemia and mortality IgG levels $<6 \mathrm{~g} / \mathrm{l}$ and $>4 \mathrm{~g} / \mathrm{l}$ were determined in 86 severe sepsis patients (47.7\%) and 11 patients with septic shock (52.3\%; $\mathrm{p}=\mathrm{NS})$. IgG levels $<4 \mathrm{~g} / \mathrm{l}$ were documented in 28 patients with severe sepsis (6.1\%) and in 2 patients with septic

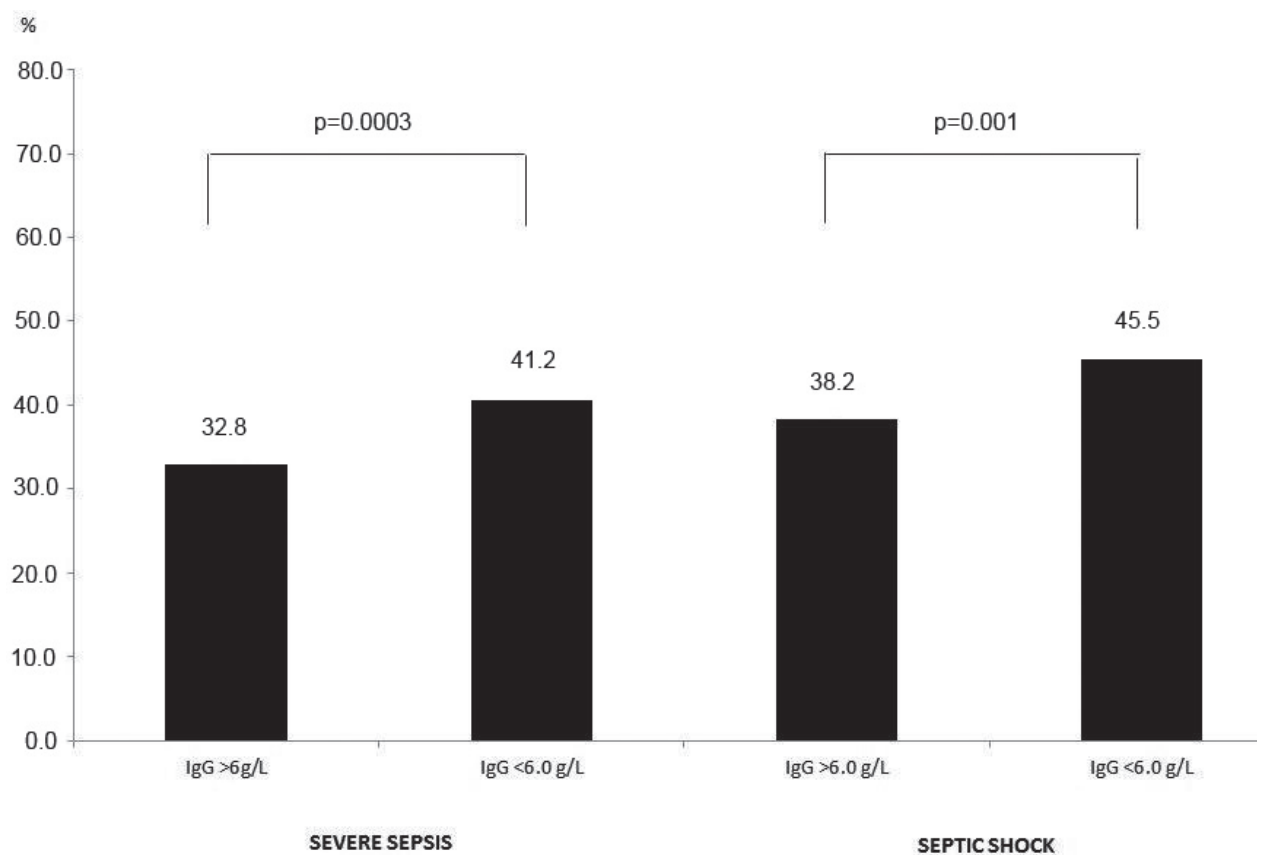

Figure 1 - Mortality of patients with hypogammaglobulinemia $\lg G$. 


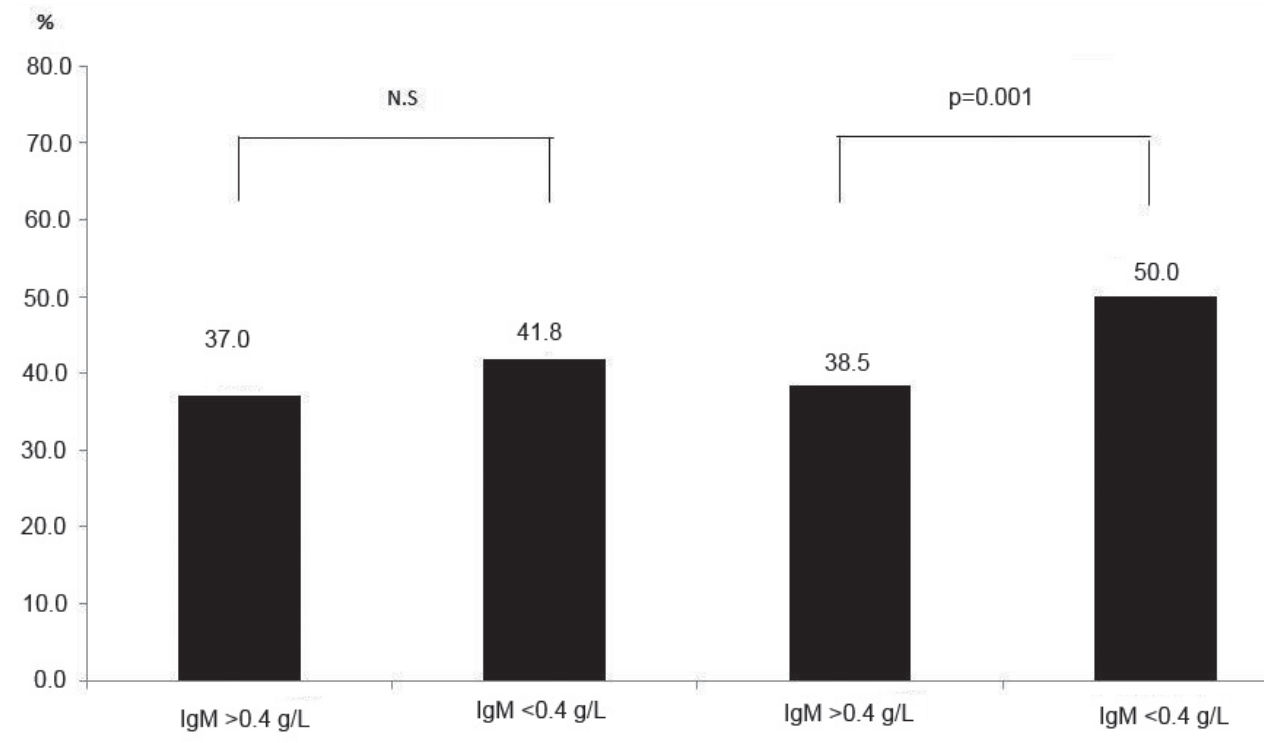

Figure 2 - Mortality of patients with hypogammaglobulinemia $\lg M$.

shock (2.9\%; $\mathrm{p}=\mathrm{NS}$ ). Among SIRS patients IgG levels of 4-6 g/l were found in 22 patients (10.5\%) while lgG levels $<4 \mathrm{~g} / \mathrm{l}$ were present in 7 patients $(3.3 \%)$.

Mortality of patients with severe sepsis and IgG hypogammaglobulinemia 4-6 g/l was significantly lower (47.7\%) compared with patients shown to have IgG levels < $4 \mathrm{~g} / \mathrm{l}(64.3 \%$; $\mathrm{p}=0.001)$. Among SIRS survivors, IgG hypogammaglobulinemia was present in 17 patients (10\%) whereas among deceased patients was present in 12 patients $(30 \% ; \mathrm{p}=0.001)$.

\section{Discussion}

Our study showed the prevalence of hypogammaglobulinemia was significantly increased in patients with sepsis and septic shock as well as in SIRS patients. Another important finding was that of an association between hypogammaglobulinemia and increased mortality rates of patients. The issue of presence of hypogammaglobulinemia in sepsis patients is of utmost importance, as intravenous immunoglobulin (IVIG) administration is one of the few options available to modulate the immunodeficiency developing in some patients.

The results of our study demonstrating that the incidence of hypogammaglobulinemia in septic shock patients is consistent with data reported by Taccone et al. (2009) and Myrianthefs et al. (2010). Both authors provided evidence of hypogammaglobulinemia in septic shock patients. Our findings in patients with severe sepsis and SIRS are unique in this respect. 
The cause of decreased antibody levels in sepsis patients is multifactorial. Systemic infection is associated with increased antibody consumption due to neutralization of endotoxins and exotoxins, and bacterial clearance. Another reason for low antibody levels is decreased rates of $B$ cells associated with sepsis. Hotchkiss and colleagues (1999) demonstrated in sepsis patients that immunecell death and depletion was also mediated through apoptosis. A prospective study in adult patients compared spleens obtained either intraoperatively or within 6 hours of death from sepsis or trauma, and found that those from septic patients showed a marked decrease in B cells. Further, the rate of antigen-specific antibody production is also decreased already in the early phase of systemic infection (Mohr et al., 2012). Other factors involved in the decrease in antibody levels in the vascular bed include enhanced vascular permeability and increased catabolism rates. Compared with the study by Taccone et al. (2009), the incidence of hypogammaglobulinemia was markedly lower in our study, with our results comparable with those of the Greek authors. Our study did not include patients with community-acquired septic shock; they were exclusively patients with ICU-acquired septic shock. Systemic inflammatory response syndrome patients were those undergoing cardiac surgery and general surgery procedures. These patients may have developed hypogammaglobulinemia secondary to blood losses occurring during surgery.

An important finding of our study is the association between hypogammaglobulinemia and increased mortality in all three subgroups of patients, i.e. those with severe sepsis, septic shock, and SIRS. In this context, one should ask whether it is the hypogammaglobulinemia which is the cause of increased mortality rates, or it is just an epiphenomenon of these serious conditions. Based on the results of our and other studies conducted to date, no conclusive answer can be provided. If assessing patients with other diagnoses related to decreased rates of antibody production, there is a clear association between decreased antibody levels and incidence of infections. For example, the diagnosis of common variable immunodeficiency (CVID) is associated with frequent development of severe infection (Oksenhendler et al., 2008). Because of the permanently impaired antibody production, these patients are doomed to lifelong IVIG administration. Another group of patients with impaired antibody production are those with chronic lymphatic leukemia. Intravenous immunoglobulin administration, while decreasing the incidence of severe infection, has no impact on mortality in this population (Raanani et al., 2009).

Our study clearly documented an association between mortality and present $\lg \mathrm{G}$ hypogammaglobulinemia. This association varied depending on the severity of hypogammaglobulinemia and diagnosis (severe sepsis or septic shock). Higher mortality rates were demonstrated in patients with severe sepsis and IgG hypogammaglobulinemia, while mortality of patients with $\operatorname{lgG}$ levels $<4 \mathrm{~g} / \mathrm{l}$ was higher than that of individuals with $\lg G$ levels of $4-6 \mathrm{~g} / \mathrm{l}$. Similarly, we documented 
increased mortality rates in patients with IgG hypogammaglobulinemia and septic shock. Still, there was no difference in mortality between patients with IgG levels of $4-6 \mathrm{~g} / \mathrm{l}$ and those with IgG levels $<4 \mathrm{~g} / \mathrm{l}(44.2 \%$ vs. $50 \%$ resp.). This might suggest a different impact of documented IgG hypogammaglobulinemia in these two disease entities of different clinical relevance. No assessment of IgA hypogammaglobulinemia was made in our study because of the small number of patients. Mortality rates of patients with documented IgM hypogammaglobulinemia were appreciably higher comparing to patients with euglobulinemia IgM in the septic shock subgroup, while not being markedly different in the subgroup with severe sepsis. Here again, one could speculate about a different impact on IgM hypogammaglobulinemia on mortality in terms of clinical outcome in patients with severe sepsis or septic shock. However, it should be underlined, when assessing the importance of different mortality rates in documented IgM hypogammaglobulinemia, the total number of patients with documented IgM hypogammaglobulinemia was low, a mere 6 patients, hence caution should be exercised when considering the different mortality rates.

The above facts necessarily make one to ask another question. Does the presence of hypogammaglobulinemia require IVIG administration? Based on the differences in the mortality of patients "with" and "without" hypogammaglobulinemia, this question seems to be most reasonable, particularly if considering the seriousness of hypogammaglobulinemia and established diagnosis. However, IVIG use in sepsis patients has long been the subject of controversy. Current guidelines do not recommend IVIG use as a routine part of the management of sepsis (Dellinger et al., 2013), however this recommendation is not specifically formulated for septic patients with hypogammaglobulinemia. The effect of IVIG use in septic patients was recently examined in three meta-analyses. It should be noted that, in the studies, IVIG was administered regardless of the presence/absence of hypogammaglobulinemia. The meta-analysis by Laupland et al. (2007) evaluated 14 randomized trials published between 1988 and 2006. The studies included patients with severe sepsis or septic shock, and assessed the effect of IVIG on mortality. The meta-analysis demonstrated a significant reduction in mortality in IVIG-treated patients (odds ratio $0.66 ; 95 \% \mathrm{Cl} 0.53-0.83 ; p<0.0005$ ). A greater therapeutic effect was seen in studies of inferior quality in terms of methodology and in studies with higher IVIG doses. Turgeon et al. (2007) evaluated studies published between 1996 and 2006. Of the 4,096 identified studies the authors selected 20 with 2,621 patients, and documented a beneficial effect of IVIG used on mortality ( $R R$ ratio $0.74 ; 95 \% \mathrm{Cl} 0.62-0.89 ; p=0.001)$. A meta-analysis by Kreymann et al. (2007) also showed a beneficial effect of IVIG administration on mortality in adult patients ( $\mathrm{RR} 0.79 ; \mathrm{Cl} 0.69-0.90 ; \mathrm{p}<0.0003)$ as well as in a population of children and neonates ( $R R \quad 0.56 ; 95 \% \mathrm{Cl} 0.42-0.74 ; p<0.0001$ ). By contrast, the multicentric SBTIS (score-based immunoglobulin G therapy of patients with sepsis) trial (653 patients) did not show a beneficial effect of IVIG 
use on mortality if given at a dose of $0.9 \mathrm{~g}$ per weight in $\mathrm{kg}$ (Werdan et al., 2007). Consistent with data from clinical trials, it has long been assumed that IVIG use in newborns with sepsis is clearly beneficial. However, an Australian, well-designed multicentric trial published in 2011 did not show a beneficial effect of IVIG on mortality of septic newborns (INIS Collaborative Group, 2011).

Despite this, some centers do use IVIG on a routine basis. An Italian study demonstrated the benefit of IgM-containing IVIG use in the early phase of severe sepsis and septic shock (Berlot et al., 2012), and a study by Rankin et al. (2011) suggested a beneficial effect of IVIG in patients undergoing cardiac surgery.

A special group of infectious disease and/or sepsis embraces streptococcal and staphylococcal septic shock and necrotizing staphylococcal lung infection with documented Panton-Valentine leucocidin (Raithatha and Bryden, 2012). Patients with these conditions should be treated with IVIG at a dose of $1-2 \mathrm{~g} / \mathrm{kg}$ weight for 3 days. It should be noted that experiments have shown a smaller effect of polyclonal immunoglobulins on the inhibition of the staphylococcal superantigen compared with the streptococcal one; hence the recommendation to use a higher dose in patients with staphylococcal septic shock. While no large randomized trials have been published to date, occasional case reports suggest the usefulness of IVIG treatment (Darenberg et al., 2004).

A recent publication reported the identification of a new population of $B$ lymphocytes playing a major role in antibody production and protection against infection (Rauch et al., 2012). In contrast, another experimental study did not demonstrate a major impact of functional antibody immunity on the outcome in sepsis. The absence of functional B lymphocyte had no effect on mortality of animals with sepsis (Bosmann et al., 2011).

Also relevant is the balance - or imbalance of pro- and anti-inflammatory activity present in sepsis. An argument raised against intravenous immunoglobulins is their non-standard nature (Vassilev and Bauer, 2012) due to the technique of their production. This non-standard nature is potentially related to the presence of antigen-specific antibody in these products. However, as regards their immunomodulatory action, it has been shown that the IVIGs marketed by different manufacturers act via a uniform mechanism based on modulated signalling (Maddur et al., 2013). Regarding the mechanisms of the immunomodulatory actions, a pivotal tole is played by the IgG Fc receptor (Smith and Clatworthy, 2010). To date, three

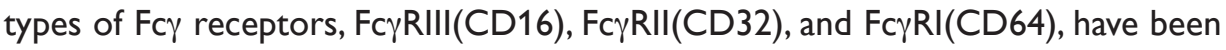
identified. These receptors are expressed on immunocompetent cells and are currently viewed as one of the most important regulators of the immune response. In terms of immunity regulation, the dominant receptor among the above three is Fc $\gamma$ RII. Various forms of the Fc $\gamma R$ II receptor have been identified, each having

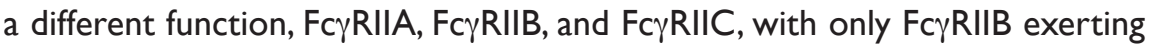
an inhibitory action. This immunomodulatory function comes into play should infection or inflammatory autoimmune disease develop. In the case of infection, 
the orchestrated action of $\lg G$ antibody bound to the pathogen and activated $\mathrm{F} c \gamma$ receptor results in pathogen removal via a process referred to as antibodydependent cell-mediated cytotoxicity (ADCC). The Fc $\gamma$ receptors are also involved in toxin neutralization by binding to IgG antibody. As regards infectious disease, there is evidence that FcyRIIB affects not only pathogen clearance but, also, the intensity of the inflammatory response and/or transition from infection control to uncontrolled SIRS and septic shock (Anthony et al., 2011). In a very recent study using a model with transgenic mice, the authors showed that the anti-inflammatory effect of IVIG is based on modulation of IL-33 and IL-4 expression (increased production) with subsequent modulation of $\mathrm{Fc} \gamma \mathrm{R}$ IIB receptor expression. The result is suppression of antibody-mediated inflammation (Chong and Chong, 2010). Hence, the mechanism is based on opposing inflammation through the Th2 immune response, a pathway with interesting implications in the area of IVIG immunomodulatory action in sepsis.

Recently, there has again been debate over the issue of comparing the efficacy of IgM-enriched IVIGs (Pentaglobin). According to some studies, this therapeutic option is more effective than therapy using conventional polyvalent IgG agents (Yavuz et al., 2012). In this context, an interesting finding was reported by an experimental study comparing IVIG with selectively removed isotype IgG versus IgM antibodies, with higher mortality rates shown in the arm of animals treated with IVIG with selectively removed isotype IgG antibodies (Moitra et al., 2012).

Our study does not provide an answer to the question of IVIG administration as the participating centers were not consistent in indicating IVIG use making evaluation of any therapeutic effect impossible.

Our study has some limitations. Given its retrospective nature, we were unable to assess the IgG subclass levels and their potential association with mortality data. Regarding the different immunoglobulin substitution policy in the hospitals, we only assessed the initial immunoglobulin level so these would not be confounded by any subsequent administration of IVIG. Neither did we assess the effect of IVIG use on mortality in patients with documented IgG hypogammaglobulinemia.

In conclusion, we documented relatively high frequency of hypogammaglobulinemia $\lg G$ and $\lg M$ in patients with severe sepsis, septic shock and SIRS respectively. The presence of IgG hypogammaglobulinemia in patients with severe sepsis is an independent factor of mortality. The role of hypogammaglobulinemia in patients with severe sepsis and septic shock as well as in some patients with SIRS of non-infectious etiology clearly warrants future controlled clinical trials with IVIG use in these patient populations.

\section{References}

Alejandria, M. M., Lansang, M. A., Dans, L. F., Mantaring lii, J. B. (2013) Intravenous immunoglobulin for treating sepsis, severe sepsis and septic shock. Cochrane Database Syst. Rev. 9:CD001090, doi: 10.1002/14651858 .CD001090.pub2. 
Anthony, R. M., Kobayashi, T., Wermeling, F., Ravetch, J. V. (2011) Intravenous gammaglobulin suppresses inflammation through a novel $\mathrm{T}(\mathrm{H}) 2$ pathway. Nature 475, 110-113.

Berlot, G., Vassallo, M. C., Busetto, N., Bianchi, M., Zornada, F., Rosato, I., Tartamella, F., Prisco, L., Bigotto, F., Bigolin, T., Ferluga, M., Batticci, I., Michelone, E., Borelli, M., Viviani, M., Tomasini, A. (2012) Relationship between the timing of administration of $\lg M$ and $\lg A$ enriched immunoglobulins in patients with severe sepsis and septic shock and the outcome: a retrospective analysis. J. Crit. Care 27, 167-171.

Bosmann, M., Russkamp, N. F., Patel, V. R., Zetoune, F. S., Sarma, J. V., Ward, P. A. (2011) The outcom of polymicrobial sepsis is independent of T and B cells. Shock 36, 396-340.

Casadevall, A., Pirofski, L. A. (2011) A new synthesis for antibody-mediated immunity. Nat. Immunol. 13, $21-28$.

Chong, B. H., Chong, J. J. H. (2010) IVIg immune inhibitory activity: APC is key. Blood 115, 1663-1664.

Darenberg, J., Söderquist, B., Normark, B. H., Norrby-Teglund, A. (2004) Differences in potency of intravenous polyspecific immunoglobulin $\mathrm{G}$ against streptococcal and staphylococcal superantigens: implications for therapy of toxic shock syndrome. Clin. Infect. Dis. 38, 836-842.

Dellinger, R. P., Levy, M. M., Rhodes, A., Annane, D., Gerlach, H., Opal, S. M., Sevransky, J. E., Sprung, C. L., Douglas, I. S., Jaeschke, R., Osborn, T. M., Nunnally, M. E., Townsend, S. R., Reinhart, K., Kleinpell, R. M., Angus, D. C., Deutschman, C. S., Machado, F. R., Rubenfeld, G. D., Webb, S., Beale, R. J., Vincent, J. L., Moreno, R.; Surviving Sepsis Campaign Guidelines Committee including The Pediatric Subgroup (2013) Surviving Sepsis Campaign: international guidelines for management of severe sepsis and septic shock, 2012. Intensive Care Med. 39, 165-228.

Hotchkiss, R. S., Swanson, P. E., Freeman, B. D., Tinsley, K. W., Cobb, J. P., Matuschak, G. M., Buchman, T. G., Karl, I. E. (1999) Apoptotic cell death in patients with sepsis, shock, and multiple organ dysfunction. Crit. Care Med. 27, 1230-1251.

INIS Collaborative Group, Brocklehurst, P., Farrell, B., King, A., Juszczak, E., Darlow, B., Haque, K., Salt, A., Stenson, B., Tarnow-Mordi, W. (2011) Treatment of neonatal sepsis with intravenous immune globulin. N. Engl. J. Med. 365, 1201-1211.

Kreymann, K. G., de Heer, G., Nierhaus, A., Kluge, S. (2007) Use of polyclonal immunoglobulins as adjunctive therapy for sepsis or septic shock. Crit. Care Med. 35, 2677-2685.

Laupland, K. B., Kirkpatrick, A. W., Delaney, A. (2007) Polyclonal intravenous immunoglobulin for the treatment of severe sepsis and septic shock in critically ill adults: A systematic review and meta-analysis. Crit. Care Med. 35, 2686-2692.

Levy, M. M., Fink, M. P., Marshall, J. C., Abraham, E., Angus, D., Cook, D., Cohen, J., Opal, S. M., Vincent, J. L., Ramsay, G. (2003) 2001 SCCM/ESICM/ACCP/ATS/SIS International Sepsis Definitions Conference. Intensive Care Med. 29(4), 530-538.

Lucas, M., Lee, M., Lortan, J., Lopez-Granados, E., Misbah, S., Chapel, H. (2010) Infection outcomes in patients with common variable immunodeficiency disorders: relationship to immunoglobulin therapy over 22 years. J. Allergy Clin. Immunol. 125, 1354-1360.

Maddur, M. S., Sharma, M., Hegde, P., Lacroix-Desmazes, S., Kaveri, S. V., Bayry, J. (2013) Inhibitory effect of IVIG on IL-17 production by Th17 cells is independent of anti-IL-17 antibodies in the immunoglobulin preparations. J. Clin. Immunol. 33, S62-S66 (Suppl. 1).

Mohr, A., Polz, J., Martin, E. M., Griessl, S., Kammler, A., Pötschke, C., Lechner, A., Bröker, B. M., Mostböck, S., Männel, D. N. (2012) Sepsis leads to a reduced antigen-specific primary antibody response. Eur. J. Immunol. 42, 341-352.

Moitra, R., Beal, D. R., Belikoff, B. G., Remick, D. G. (2012) Presence of preexisting antibodies mediates survival in sepsis. Shock 37, 56-62.

Myrianthefs, P. M., Boutzouka, A., Baltopoulos, G. J. (2010) $\gamma$-globulin levels in patients with communityacquired septic shock. Shock 33, 556-557.

Průcha M.; Zazula R.; Herold I.; Dostál M.; Hyánek T.; Bellingan G. 
Oksenhendler, E., Gérard, L., Fieschi, C., Malphettes, M., Mouillot, G., Jaussaud, R., Viallard, J. F., Gardembas, M., Galicier, L., Schleinitz, N., Suarez, F., Soulas-Sprauel, P., Hachulla, E., Jaccard, A., Gardeur, A., Théodoro, I., Rabian, C., Debré, P. (2008) DEFI Study Group. Infections in 252 patients with common variable immunodeficiency. Clin. Infect. Dis. 46, 1547-1554.

Raanani, P., Gafter-Gvili, A., Paul, M., Ben-Bassat, I., Leibovici, L., Shpilberg, O. (2009) Immunoglobulin prophylaxis in chronic lymphocytic leukemia and multiple myeloma: systematic review and meta-analysis. Leuk. Lymphoma 50, 764-772.

Raithatha, A. H., Bryden, D. C. (2012) Use of intravenous immunoglobulin therapy in the treatment of septic shock, in particular severe invasive group A streptococcal disease. Indian J. Crit. Care Med. 16, 37-40.

Rankin, J. S., Oguntolu, O., Binford, R. S., Trochtenberg, D. S., Muhlbaier, L. H., Stratton, C. W. (2011) Management of immune dysfunction after adult cardiac surgery. J. Thorac. Cardiovasc. Surg. 142, 575-580.

Rauch, P. J., Chudnovskiy, A., Robbins, C. S., Weber, G. F., Etzrodt, M., Hilgendorf, I., Tiglao, E., Figueiredo, J. L., Iwamoto, Y., Theurl, I., Gorbatov, R., Waring, M. T., Chicoine, A. T., Mouded, M., Pittet, M. J., Nahrendorf, M., Weissleder, R., Swirski, F. K. (2012) Innate response activator B cells protect against microbial sepsis. Science 335, 597-601.

Smith, K. G., Clatworthy, M. R. (2010) FcgammaRIIB in autoimmunity and infection: evolutionary and therapeutic implications. Nat. Rev. Immunol. 10, 328-343.

Taccone, F. S., Stordeur, P., De Backer, D., Creteur, J., Vincent, J. L. (2009) Gamma globulin levels in patients with community acquired septic shock. Shock 32, 379-385.

Turgeon, A. F., Hutton, B., Fergusson, D. A., Mclntyre, L., Tinmouth, A. A., Cameron, D. W., Hébert, P. C. (2007) Meta-analysis: intravenous immunoglobulin in critically ill adult patients with sepsis. Ann. Intern. Med. 146, 193-201.

Vassilev, T., Bauer, M. (2012) Passive immunotherapy of sepsis with intravenous immune globulin: not all IVIg preparations are created equal. Crit. Care 16, 407.

Werdan, K., Pilz, G., Bujdoso, O., Fraunberger, P., Neeser, G., Schmieder, R. E., Viell, B., Marget, W., Seewald, M., Walger, P., Stuttmann, R., Speichermann, N., Peckelsen, C., Kurowski, V., Osterhues, H. H., Verner, L., Neumann, R., Müller-Werdan, U. (2007) Score-Based Immunoglobulin Therapy of Sepsis (SBITS) Study Group: Score-based immunoglobulin G therapy of patients with sepsis: the SBITS study. Crit. Care Med. 35 , 2693-2701.

Yavuz, L., Aynali, G., Aynali, A., Alaca, A., Kutuk, S., Ceylan, B. G. (2012) The effects of adjuvant immunoglobulin $M$-enriched immunoglobulin therapy on mortality rate and renal function in sepsisinduced multiple organ dysfunction syndrome: retrospective analysis of intensive care unit patients. J. Int. Med. Res. 40, 1166-1174. 